Review Article

\title{
Impact of Umbilical Cord Blood-Derived Mesenchymal Stem Cells on Cardiovascular Research
}

\author{
Santiago Roura, ${ }^{1}$ Josep Maria Pujal, ${ }^{2}$ Carolina Gálvez-Montón, ${ }^{1}$ and Antoni Bayes-Genis ${ }^{1,3,4}$ \\ ${ }^{1}$ ICREC Research Program, Germans Trias i Pujol Health Science Research Institute, Can Ruti Campus, 08916 Badalona, Spain \\ ${ }^{2}$ Cell Processing Laboratory, Parc Científic i Tecnologic Universitat de Girona, 17003 Girona, Spain \\ ${ }^{3}$ Cardiology Service, Germans Trias i Pujol University Hospital, 08916 Badalona, Spain \\ ${ }^{4}$ Department of Medicine, UAB, Barcelona, Spain \\ Correspondence should be addressed to Santiago Roura; sroura@igtp.cat and Antoni Bayes-Genis; abayesgenis@gmail.com
}

Received 25 November 2014; Accepted 11 January 2015

Academic Editor: Nicole Rotter

Copyright (c) 2015 Santiago Roura et al. This is an open access article distributed under the Creative Commons Attribution License, which permits unrestricted use, distribution, and reproduction in any medium, provided the original work is properly cited.

\begin{abstract}
Over the years, cell therapy has become an exciting opportunity to treat human diseases. Early enthusiasm using adult stem cell sources has been tempered in light of preliminary benefits in patients. Considerable efforts have been dedicated, therefore, to explore alternative cells such as those extracted from umbilical cord blood (UCB). In line, UCB banking has become a popular possibility to preserve potentially life-saving cells that are usually discarded after birth, and the number of UCB banks has grown worldwide. Thus, a brief overview on the categories of UCB banks as well as the properties, challenges, and impact of UCB-derived mesenchymal stem cells (MSCs) on the area of cardiovascular research is presented. Taken together, the experience recounted here shows that UCBMSCs are envisioned as attractive therapeutic candidates against human disorders arising and/or progressing with vascular deficit.
\end{abstract}

\section{Introduction}

Over the years, cell therapy has become an exciting opportunity to treat human diseases [1-4]. In line, considerable preclinical efforts have been dedicated to exploring valuable stem cell sources, including those from umbilical cord blood (UCB). In this context, UCB extraction as well as banking is a way to preserve potentially life-saving cells that are usually discarded after birth and has become a popular possibility among expectant parents thinking about promising options to secure their child's life. But what benefit is associated with the long and high-cost procedure that is necessary to isolate and store cells for 25 to 30 years? Public banks offer the option of altruistic donation, whereas in private banks cellular products are conserved for own use. Hybrid models blending aspects of both public and private banking are also currently intended. However, there are questions regarding the cost versus the benefits of UCB banking, and it also raises complex ethical and legal issues. Given the variety of existing options and familial and personal interests, there is a definite need for careful regulation of UCB banking and applications [5-7].

In the following pages of this review we recount some of the most relevant issues regarding categories of UCB processing laboratories and banks, as well as the properties, challenges, and impact of UCB-derived mesenchymal stem cells (MSCs) on the area of cardiovascular research.

\section{Categories of UCB Banks}

The processing of large numbers of UCB units is partially automated. In brief, once UCB samples arrive at processing laboratory, a cell suspension enriched with mononuclear cells-where the stem cell population resides in-is collected following sedimentation of red blood cells and centrifugation under high sterile conditions. The resultant cell product is cryopreserved following a controlled rate freezing process to slowly reduce the temperature to $-180^{\circ} \mathrm{C}$ and stored in liquid nitrogen dewars $[8,9]$. Alternatively, for subsequent isolation 
and expansion of mesenchymal-like stem cell colonies, 30\% fetal calf serum, low-glucose DMEM medium supplemented with $10^{-7} \mathrm{M}$ dexamethasone, and closed system applying cell stacks are used. The resultant cell product can also be stored frozen, thawed, and expanded further in clinical grade quality $[10,11]$.

In order to appropriately preserve donated units for human therapies, a number of UCB banks have been created worldwide [6]. Originally, these laboratories were run by hospitals or nonprofit institutions, which processed the donated samples and provided cells to patients when needed. Accredited "public" UCB banks were subsequently linked to national registries, which in turn were linked to international inventories. This coordination has favored the identification of the most suitable sample for each patient who requires a transplant [6]. More recently, because private companies have been offering UCB storage for own use or for the use of close relatives, UCB banks can be classified into the following categories: private or public and for-profit or nonprofit. By definition, public (nonprofit) banks store UCB-derived cells and provide them when transplantation is prescribed to patients without regard for filial relationships, while private firms offer a commercial service to parents to preserve UCBderived cells for expected progeny. However, alternatives to private banks have recently emerged. These include mixed or hybrid private-public banks, such as that proposed by the Virgin Health Bank; in the Spanish system, autologous samples can be stored and are given to individuals other than the donor if required $[6,7]$.

\section{UCBMSCs: Properties and Challenges}

UCB is currently considered the most plentiful stem cell reservoir for clinical applications $[12,13]$. Although used mainly for hematopoietic progenitor cell (HPC) transplantation against blood disorders, the spectrum of diseases for which UCB provides effective therapy has been expanded to include nonhematopoietic conditions, including cell-based regenerative therapy and immune modulation. This undeniable fact is being reinforced because, as mentioned above, UCB also contains MSCs. MSCs were sought to be present in UCB at a low frequency in contrast to their presence in other tissues throughout the body, including bone marrow, adipose tissue, placenta, dermis, and umbilical cord [14-19]. However, transplantation of double partially HLA-matched UCB units is recognized as a simple approach for overcoming this marked limitation $[12,13]$. Remarkably, recent work shows that MSCs can also be expanded successfully from $30 \%$ to $60 \%$ of low-volume UCB units [20]. In terms of advantages, UCB can be safely and painlessly extracted and long-term cryopreserved and has a lower risk of transmitting viral infections or somatic mutations than adult tissues (i.e., bone marrow).

Commonly, MSCs are recognized by their capability to differentiate into osteogenic, chondrogenic, and adipogenic lineages in vitro, typical mesenchymal-like morphology, adherence to plastic when maintained in standard culture conditions, and nonhematopoietic cell surface pattern according to the International Society of Cellular Therapy
(ISCT) criteria [21]. Distinct populations of mesenchymallike stem cells with similar adhesion properties and antigen surface expression patterns but different pluripotency have been isolated from UCB. In brief, Kögler et al. described intrinsically pluripotent or unrestricted somatic cells with the potential to reprogram into mesodermal, endodermal, and ectodermal fates [22]. Subsequently, other investigators used MSCs from UCB with more restricted pluripotency [23]. These "conflicting" data show the great cell heterogeneity in terms of growth and differentiation potential that has a major impact on the envisioned therapeutic application of MSCs, including those from UCB [24]. Since the ISCT-proposed criteria were published in 2006, some advances have been performed in an attempt to decrease substantial ambiguities in MSC definition and verification. As a result, additional cell surface markers such as STRO-1, CD271, CD200, Ganglioside GD2, Frizzled-9, and tissue nonspecific alkaline phosphatase have been included to verify identity of the isolated cells. Furthermore, together with specific staining after trilineage differentiation, the use of commercially available functional kits provides a systematic verification of MSC identity, independently of the tissue or species type.

In the context of cell-based therapies, due to their great proliferative activity, less culture time is required to get a fixed number of ex vivo expanded UCBMSCs and, therefore, fewer chances to apoptotic features. Taking into account that MSCs possess the greatest degree of multipotency, there is a need to standardize MSC isolation and culture procedures. For example, enzymatic or explant-based methods may not lead to the same cell types [25-28]. In addition, although human MSCs do not undergo malignant transformation during in vitro expansion $[29,30]$, they experience replicative senescence and mutational acquisition [30, 31]. Remarkably, Bellayr et al. have identified specific markers that distinguish aging bone marrow MSCs grown in cell culture [32]. These authors argue that confirmatory studies are needed to develop specific assays to test the quality of MSCs before any clinical use. Other options could be based on tissue transposition directly to regeneration-desired sites without stem cell extraction and long-term culture.

Moreover, solid organ transplantation is the unique solution for end-stage organ failure. Only in 2012, it is estimated that about 115,000 solid organ transplants were performed worldwide [33]. However, alternative treatments to the chronic use of immunosuppressive drugs in order to avoid rejection episodes conducted by the recipient's immune system and increase donor-specific tolerance are under investigation. They include different types of regulatory cells, for example, MSCs which have been evaluated with promising results [34]. In terms of immunogenicity, UCBMSCs have inherent "immunoprivileged" properties. UCBMSCs are characterized to express class I human leukocyte antigens (HLA antigens), whereas class II HLA antigens are expressed only after sustained exposure to interferon- $\gamma$ [35-38]. The lower immunogenicity of UCBMSCs is attributed to its immaturity, in contrast to alternative adult stem cell sources. Accordingly, UCBMSCs may be used for allogeneic transplantation [39]. However, recent findings on MSCs inducing a systemic inflammatory response within hours after infusion 
[40] need to be tested using those from UCB and likely solved for the application of these cells into the clinic.

\section{UCBMSCs and Cardiovascular Diseases: An Active Area of Research}

Since MSCs were reported to differentiate in vitro into a myogenic phenotype, the benefit of treating ischemic and nonischemic cardiovascular disorders with these cells (mainly those extracted from bone marrow) has been demonstrated and supported with compelling evidence [41]. Briefly, paramount milestones in this field include the differentiation of bone marrow-derived MSCs into cardiomyocyte-like cells in vitro [42]; the implantation of autologous MSCs cultured from bone marrow into a rat heart at 3 weeks after cryoinjury [43]; a report that described progress after 10 years of cellbased cardiac repair [44]; and, most recently, the Cardiopoietic stem Cell therapy in heart failURE (C-CURE) clinical trial based on the use of autologous bone marrow-derived and cardiogenically oriented MSCs in patients with chronic heart failure [45].

In addition, UCBMSCs are actively being used in the cardiovascular area of study. The most relevant preclinical and clinical studies using these cells are discussed below. In line, some of the experiences reported in this field of research are collectively summarized in Figure 1.

4.1. Preclinical Studies. In the preclinical setting, for instance, Erices et al. investigated the homing capacity of transplanted human UCBMSCs in the bone marrow of unconditioned nude mice. As a result, after systemic infusion, they also found human DNA in cardiac muscle, as well as in other recipient tissues [46]. Since then, one central unanswered question has been whether these cells have cardiomyogenic potential. Although several investigators have reported the differentiation of UCBMSCs into the cardiomyogenic lineage in vitro $[47,48]$, others have failed to demonstrate such differentiation $[49,50]$ using a broad range of procardiogenic stimuli, including 5-azacytidine [48], dimethyl sulfoxide [49], a combination of growth factors involved in early cardiomyogenesis [50], activation of Wnt signaling pathways [51,52], and coculture with neonatal rat cardiomyocytes [53]. A coculture system using rat cardiomyocytes had been effective in inducing a cardiomyocyte-like phenotype in $\mathrm{CD}_{133^{+}}$hematopoietic progenitors that were first selected from UCB by immunomagnetic separation and then expanded by stimulation with platelet-derived and epidermal growth factors [54]. When cultured for up to 4 weeks in a cardiac differentiationpromoting medium, this same cell population gained the expression of a variety of paramount cardiac-specific proteins [55]. However, other authors did not find that direct contact with neonatal rat cardiomyocytes promoted either the expression of cardiomyocyte-specific proteins, or the presence of rhythmic calcium oscillations and potentialdependent fluorescence emission in UCBMSCs [50]. Thus, they concluded that alternative strategies, regulatory factors, or signaling clues might be better suited to recruit UCBMSCs into the cardiac cell lineage. Surprisingly, a nonhematopoietic cellular subpopulation within the mononuclear cell fraction

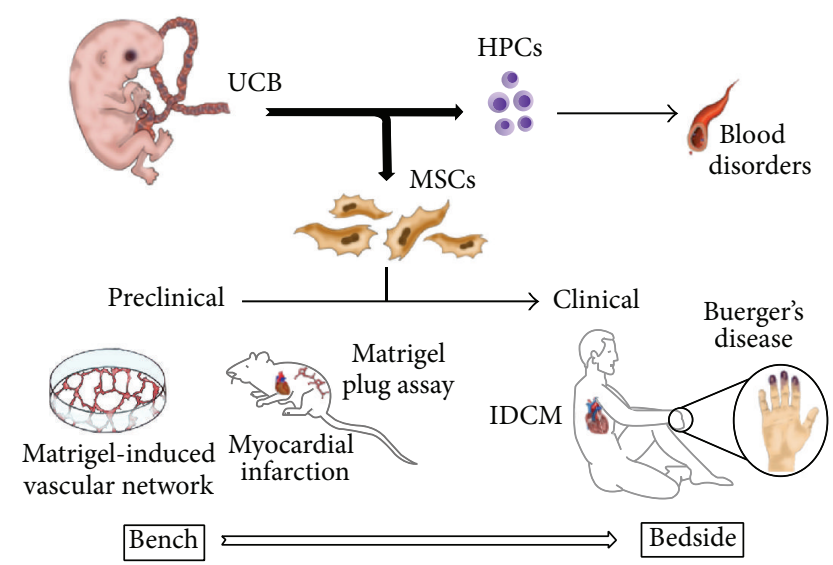

FIGURE 1: Use of UCBMSCs in the field of cardiovascular research. Scheme summarizing the main preclinical and clinical settings in which UCBMSCs are being employed. In brief, since the first transplant in 1988, UCB has increasingly been employed as an alternative source of HPCs for transplantation against human blood diseases. UCB also contains MSCs which have garnered a great deal of attention to treat cardiovascular diseases such as idiopathic dilated cardiomyopathy and Buerger's disease. Additionally, considerable preclinical efforts have been directed to explore basic UCBMSC properties and molecular mechanisms in vitro, as well as their behavior and functions once implanted in vivo. UCB: umbilical cord blood; HPC: hematopoietic progenitor cell; MSC: mesenchymal stem cell; IDCM: idiopathic dilated cardiomyopathy. Designed and hand-drawn by Carolina Gálvez-Montón.

isolated from UCB was differentiated towards the cardiomyogenic lineage after these cells were cocultured with brown adipose tissue-derived cells [56]. Further details about the cardiomyogenic potential of UCBMSCs from ongoing investigations will have to shine light on this essential question and allow the design of effective cardiac cell therapy using these cells.

In recent times, several authors have suggested that MSCs may also play a role in vascular growth, garnering a great deal of attention for therapeutic purposes [14]. In line, intramyocardially administered $\mathrm{CD}_{105}{ }^{+}$UCBMSCs exhibited favorable survival in infarcted mouse hearts, which translates into better capillary density in both border and remote zones 6 weeks after infarction and more robust preservation of cardiac function [57]. Lee et al. also found that $\mathrm{N}$-cadherin determines individual variations in the therapeutic efficacy of human UCBMSCs in a rat myocardial infarction model and that variations in capillary density are correlated with therapeutic efficacy in improving left ventricular function [58].

Currently, noninvasive techniques such as bioluminescence imaging, which is based on the application of natural reactants with light-emitting capabilities (photoproteins and luciferases), provide valuable information about cardiac cell transplantation in living animals [59]. Indeed, combination of this advanced nondestructive imaging technique with reporter gene technology has been useful to improve outcomes of cell therapies in the field of cardiac regeneration. This is, for instance, the case of the monitoring of chimeric luciferase/fluorescent protein expression by human 
engineered UCBMSCs in a mouse model of angiogenesis (Matrigel Plug Assay) [60]. In particular, an efficient differentiation of these genetically modified cells into the endothelial cell lineage was demonstrated. The implanted cells also selforganized into new functional blood vessels connected with the host circulatory system; these newly formed vascular structures were filled with high molecular weight FITCdextran injected through the lateral tail vein of mice before sacrifice. In the same study, engineered UCBMSCs were mixed with fibrin and applied as an adhesive patch over infarcted myocardium wound to analyze their potential benefits. As a result, the implanted cells proliferated early, survived during 4 weeks over injured myocardium, efficiently differentiated towards the endothelial lineage, and induced the development of new functional vasculature. Furthermore, although no cells were found migrating from the patch to the myocardium of infarcted animals, they formed vascular-like structures expressing CD31 (a surface endothelial cell-specific antigen). Importantly, cell-treated animals also exhibited reduced infarct size and larger vessel than controls. However, it remains to be elucidated whether the implantation of this newly designed bioprosthesis promotes a significant general recovery of lost myocardial functions after myocardial infarction.

4.2. Clinical Studies. In the clinical setting, there are UCBbased treatments for both hematological and nonhematological conditions, including neurological diseases, diabetes mellitus, hepatic/gastrointestinal alterations, skin diseases, rheumatoid arthritis, systemic lupus erythematosus, bronchopulmonary dysplasia, malignant solid tumors, hematologic malignancies, inborn metabolic disorders, orthopedic cartilage repair, and osteopetrosis [61, 62]. In particular, neurological disorders represent the most commonly published area of expertise and the most active area of study in ongoing registered trials. Furthermore distinct cell types (total nucleated cells, mononuclear cells, and CD34selected HPCs) and delivery routes (intravenous, intrathecal, subcutaneous, and intramuscular) are used [61]. To date, although being an active field of research, UCBMSCs have been less tested clinically. In the field of cardiovascular diseases, Kim and coworkers transplanted human leukocyte antigen-matched UCBMSCs into four men with Buerger's disease-a nonatherosclerotic, inflammatory, vasoocclusive disorder-who had already received medical treatment and surgical therapies [63]. After transplantation procedure, ischemic rest pain suddenly disappeared from their affected extremities and, in the follow-up angiography, digital capillaries were increased in number and size. In addition, vascular resistance in the affected extremities, compared with the preoperative examination, was markedly decreased due to improvement of the peripheral circulation. The authors concluded that implanted cells could incorporate to arterial walls of the ischemic hind limb in the treated group and suggested that the use of human UCBMSCs could be a new and useful therapeutic weapon for ischemic diseases. Moreover, we have recently showed that UCBMSCs are conceivably new therapeutic agents for patients afflicted by idiopathic dilated cardiomyopathy, in which disease progression has the signature of marked cardiac endothelial deficiencies [64].

\section{Conclusions}

Together with somatic reprogramming induced by gene transfer [65], cell therapy has been an exciting innovation to treat human diseases. However, early enthusiasm using adult stem cell sources has been tempered in light of preliminary benefits in patients. Considerable efforts have been dedicated, therefore, to explore alternative cells such as those extracted from UCB. Since the first transplant in 1988, UCB has increasingly been employed for transplantation of hematopoietic cells in blood diseases and the number of UCB banks has grown worldwide [66]. In particular, public banks offer the option of altruistic donation, whereas in private banks cellular products are conserved for own use. Hybrid models blending aspects of both public and private banking are currently planned [67]. In this context, taking into consideration the experience recounted here, UCBMSCs are also envisioned as attractive therapeutic candidates against human disorders, for example, those arising and/or progressing mainly by vascular deficits.

\section{Conflict of Interests}

The authors declare that there is no conflict of interests regarding the publication of this paper.

\section{Acknowledgments}

This work was supported by the Ministerio de Educación y Ciencia (SAF2011-30067-C02-01), Red de Terapia Celular, TerCel (RD12/0019/0029), Red Investigación Cardiovascular, RIC (RD12/0042/0047), Fundació La Marató de TV3 (122232), and Fondo de Investigación Sanitaria, Instituto de Salud Carlos III (FIS PI14/01682).

\section{References}

[1] E. Buzhor, L. Leshansky, J. Blumenthal et al., "Cell-based therapy approaches: the hope for incurable diseases," Regenerative Medicine, vol. 9, no. 5, pp. 649-672, 2014.

[2] N. M. P. King and J. Perrin, "Ethical issues in stem cell research and therapy," Stem Cell Research \& Therapy, vol. 5, no. 4, article 85, 2014.

[3] S. W. Lane, D. A. Williams, and F. M. Watt, "Modulating the stem cell niche for tissue regeneration," Nature Biotechnology, vol. 32, no. 8, pp. 795-803, 2014.

[4] C. Telfer, "Stem cells show promise in the treatment of failing hearts," Future Cardiology, vol. 10, no. 3, article 3165, 2014.

[5] C. L. Stewart, L. C. Aparicio, and I. H. Kerridge, "Ethical and legal issues raised by cord blood banking - the challenges of the new bioeconomy," Medical Journal of Australia, vol. 199, no. 4, pp. 290-292, 2013.

[6] C. Petrini, "Umbilical cord blood banking: from personal donation to international public registries to global bioeconomy," Journal of Blood Medicine, vol. 5, pp. 87-97, 2014. 
[7] J. Aznar Lucea, "Umbilical cord blood banks. Ethical aspects. Public versus private banks," Cuadernos de Bioética, vol. 23, no. 78, pp. 269-285, 2012.

[8] N. M. Reboredo, A. Díaz, A. Castro, and R. G. Villaescusa, "Collection, processing and cryopreservation of umbilical cord blood for unrelated transplantation," Bone Marrow Transplantation, vol. 26, no. 12, pp. 1263-1270, 2000.

[9] W. Young, "Plasma-depleted versus red cell-reduced umbilical cord blood," Cell Transplantation, vol. 23, no. 4-5, pp. 407-415, 2014.

[10] G. Kögler, P. Critser, T. Trapp, and M. Yoder, "Future of cord blood for non-oncology uses," Bone Marrow Transplantation, vol. 44, no. 10, pp. 683-697, 2009.

[11] D. A. Wall, "Regulatory issues in cord blood banking and transplantation," Best Practice and Research: Clinical Haematology, vol. 23, no. 2, pp. 171-177, 2010.

[12] H. Mayani and P. M. Lansdorp, "Biology of human umbilical cord blood-derived hematopoietic stem/progenitor cells," Stem Cells, vol. 16, no. 3, pp. 153-165, 1998.

[13] H. Mayani, "Umbilical cord blood: lessons learned and lingering challenges after more than 20 years of basic and clinical research," Archives of Medical Research, vol. 42, no. 8, pp. 645651, 2011.

[14] S. M. Watt, F. Gullo, M. van der Garde et al., "The angiogenic properties of mesenchymal stem/stromal cells and their therapeutic potential," British Medical Bulletin, vol. 108, no. 1, pp. 25-53, 2013.

[15] M. F. Pittenger and B. J. Martin, "Mesenchymal stem cells and their potential as cardiac therapeutics," Circulation Research, vol. 95, no. 1, pp. 9-20, 2004.

[16] P. A. Zuk, M. Zhu, P. Ashjian et al., "Human adipose tissue is a source of multipotent stem cells," Molecular Biology of the Cell, vol. 13, no. 12, pp. 4279-4295, 2002.

[17] O. Parolini, F. Alviano, G. P. Bagnara et al., "Concise review: Isolation and characterization of cells from human term placenta: outcome of the first international Workshop on Placenta Derived Stem Cells," Stem Cells, vol. 26, no. 2, pp. 300-311, 2008.

[18] R. P. Hill, K. Gledhill, A. Gardner et al., "Generation and characterization of multipotent stem cells from established dermal cultures," PLoS ONE, vol. 7, no. 11, Article ID e50742, 2012.

[19] S. Corrao, G. la Rocca, M. lo Iacono et al., "New frontiers in regenerative medicine in cardiology: the potential of Wharton's jelly mesenchymal stem cells," Current Stem Cell Research and Therapy, vol. 8, no. 1, pp. 39-45, 2013.

[20] S. M. Watt and M. Contreras, "Stem cell medicine: umbilical cord blood and its stem cell potential," Seminars in Fetal and Neonatal Medicine, vol. 10, no. 3, pp. 209-220, 2005.

[21] M. Dominici, K. Le Blanc, I. Mueller et al., "Minimal criteria for defining multipotent mesenchymal stromal cells. The International Society for Cellular Therapy position statement," Cytotherapy, vol. 8, no. 4, pp. 315-317, 2006.

[22] G. Kögler, S. Sensken, J. A. Airey et al., "A new human somatic stem cell from placental cord blood with intrinsic pluripotent differentiation potential," Journal of Experimental Medicine, vol. 200, no. 2, pp. 123-135, 2004.

[23] M. F. Manca, I. Zwart, J. Beo et al., "Characterization of mesenchymal stromal cells derived from full-term umbilical cord blood," Cytotherapy, vol. 10, no. 1, pp. 54-68, 2008.

[24] P. Bianco, X. Cao, P. S. Frenette et al., "The meaning, the sense and the significance: translating the science of mesenchymal stem cells into medicine," Nature Medicine, vol. 19, no. 1, pp. 3542, 2013.
[25] D.-H. Lee, S.-D. Joo, S.-B. Han et al., "Isolation and expansion of synovial CD $3^{4-} \mathrm{CD} 44^{+} \mathrm{CD} 90^{+}$mesenchymal stem cells: comparison of an enzymatic method and a direct explant technique," Connective Tissue Research, vol. 52, no. 3, pp. 226-234, 2011.

[26] N. Priya, S. Sarcar, A. S. Majumdar, and S. Sundarraj, "Explant culture: a simple, reproducible, efficient and economic technique for isolation of mesenchymal stromal cells from human adipose tissue and lipoaspirate," Journal of Tissue Engineering and Regenerative Medicine, vol. 27, pp. 1-9, 2012.

[27] Y.-F. Han, R. Tao, T.-J. Sun, J.-K. Chai, G. Xu, and J. Liu, "Optimization of human umbilical cord mesenchymal stem cell isolation and culture methods," Cytotechnology, vol. 65, no. 5, pp. 819-827, 2013.

[28] P. Hilkens, P. Gervois, Y. Fanton et al., "Effect of isolation methodology on stem cell properties and multilineage differentiation potential of human dental pulp stem cells," Cell and Tissue Research, vol. 353, no. 1, pp. 65-78, 2013.

[29] G. Chen, A. Yue, Z. Ruan et al., "Human umbilical cord-derived mesenchymal stem cells do not undergo malignant transformation during long-term culturing in serum-free medium," PLoS ONE, vol. 9, no. 6, Article ID e98565, 2014.

[30] Y. Wang, Z. Zhang, Y. Chi et al., "Long-term cultured mesenchymal stem cells frequently develop genomic mutations but do not undergo malignant transformation," Cell Death and Disease, vol. 4, no. 12, article e950, 2013.

[31] W. Wagner, S. Bork, P. Horn et al., "Aging and replicative senescence have related effects on human stem and progenitor cells," PLoS ONE, vol. 4, no. 6, Article ID e5846, 2009.

[32] I. H. Bellayr, J. G. Catalano, S. Lababidi et al., "Gene markers of cellular aging in human multipotent stromal cells in culture," Stem Cell Research and Therapy, vol. 5, no. 2, article 59, 2014.

[33] Spanish National Transplant Organization (ONT) and World Health Organization (WHO), "Global Observatory on Donation and Transplantation," 2014, http://www.transplant-observatory.org/Pages/home.aspx.

[34] E. K. Geissler and J. A. Hutchinson, "Cell therapy as a strategy to minimize maintenance immunosuppression in solid organ transplant recipients," Current Opinion in Organ Transplantation, vol. 18, no. 4, pp. 408-415, 2013.

[35] C. Götherström, O. Ringdén, C. Tammik, E. Zetterberg, M. Westgren, and K. Le Blanc, "Immunologic properties of human fetal mesenchymal stem cells," American Journal of Obstetrics and Gynecology, vol. 190, no. 1, pp. 239-245, 2004.

[36] S. Aggarwal and M. F. Pittenger, "Human mesenchymal stem cells modulate allogeneic immune cell responses," Blood, vol. 105, no. 4, pp. 1815-1822, 2005.

[37] P. Comoli, F. Ginevri, R. MacCario et al., "Human mesenchymal stem cells inhibit antibody production induced in vitro by allostimulation," Nephrology Dialysis Transplantation, vol. 23, no. 4, pp. 1196-1202, 2008.

[38] G. Chamberlain, J. Fox, B. Ashton, and J. Middleton, "Concise review: mesenchymal stem cells: their phenotype, differentiation capacity, immunological features, and potential for homing," Stem Cells, vol. 25, no. 11, pp. 2739-2749, 2007.

[39] M. Lee, S. Y. Jeong, J. Ha et al., "Low immunogenicity of allogeneic human umbilical cord blood-derived mesenchymal stem cells in vitro and in vivo," Biochemical and Biophysical Research Communications, vol. 446, no. 4, pp. 983-989, 2014.

[40] M. J. Hoogduijn, M. Roemeling-Van Rhijn, A. U. Engela et al., "Mesenchymal stem cells induce an inflammatory response 
after intravenous infusion," Stem Cells and Development, vol. 22, no. 21, pp. 2825-2835, 2013.

[41] S.-H. Chou, S.-Z. Lin, W.-W. Kuo et al., "Mesenchymal stem cell insights: prospects in cardiovascular therapy," Cell Transplantation, vol. 23, no. 4-5, pp. 513-529, 2014.

[42] S. Makino, K. Fukuda, S. Miyoshi et al., "Cardiomyocytes can be generated from marrow stromal cells in vitro," Journal of Clinical Investigation, vol. 103, no. 5, pp. 697-705, 1999.

[43] S. Tomita, R.-K. Li, R. D. Weisel et al., "Autologous transplantation of bone marrow cells improves damaged heart function," Circulation, vol. 100, no. 19, pp. II247-II256, 1999.

[44] C. E. Murry, L. J. Field, and P. Menasché, "Cell-based cardiac repair reflections at the 10 -year point," Circulation, vol. 112, no. 20, pp. 3174-3183, 2005.

[45] J. Bartunek, A. Behfar, D. Dolatabadi et al., "Cardiopoietic stem cell therapy in heart failure: the C-CURE (cardiopoietic stem cell therapy in heart failURE) multicenter randomized trial with lineage-specified biologics," Journal of the American College of Cardiology, vol. 61, no. 23, pp. 2329-2338, 2013.

[46] A. A. Erices, C. I. Allers, P. A. Conget, C. V. Rojas, and J. J. Minguell, "Human cord blood-derived mesenchymal stem cells home and survive in the marrow of immunodeficient mice after systemic infusion," Cell Transplantation, vol. 12, no. 6, pp. 555561, 2003.

[47] M. Kadivar, S. Khatami, Y. Mortazavi, M. A. Shokrgozar, M. Taghikhani, and M. Soleimani, "In vitro cardiomyogenic potential of human umbilical vein-derived mesenchymal stem cells," Biochemical and Biophysical Research Communications, vol. 340, no. 2, pp. 639-647, 2006.

[48] N. Nishiyama, S. Miyoshi, N. Hida et al., "The significant cardiomyogenic potential of human umbilical cord blood-derived mesenchymal stem cells in vitro," Stem Cells, vol. 25, no. 8, pp. 2017-2024, 2007.

[49] E. Martin-Rendon, D. Sweeney, F. Lu, J. Girdlestone, C. Navarrete, and S. M. Watt, "5-Azacytidine-treated human mesenchymal stem/progenitor cells derived from umbilical cord, cord blood and bone marrow do not generate cardiomyocytes in vitro at high frequencies," Vox Sanguinis, vol. 95, no. 2, pp. 137$148,2008$.

[50] S. Roura, J. Farré, L. Hove-Madsen et al., "Exposure to cardiomyogenic stimuli fails to transdifferentiate human umbilical cord blood-derived mesenchymal stem cells," Basic Research in Cardiology, vol. 105, no. 3, pp. 419-430, 2010.

[51] T. Nakamura, M. Sano, Z. Songyang, and M. D. Schneider, "A Wnt- and $\beta$-catenin-dependent pathway for mammalian cardiac myogenesis," Proceedings of the National Academy of Sciences of the United States of America, vol. 100, no. 10, pp. 5834-5839, 2003.

[52] M. Koyanagi, J. Haendeler, C. Badorff et al., "Non-canonical Wnt signaling enhances differentiation of human circulating progenitor cells to cardiomyogenic cells," The Journal of Biological Chemistry, vol. 280, no. 17, pp. 16838-16842, 2005.

[53] C. Badorff, R. P. Brandes, R. Popp et al., “Transdifferentiation of blood-derived human adult endothelial progenitor cells into functionally active cardiomyocytes," Circulation, vol. 107, no. 7, pp. 1024-1032, 2003.

[54] J. Park, V. Setter, V. Wixler, and H. Schneider, "Umbilical cord blood stem cells: induction of differentiation into mesenchymal lineages by cell-cell contacts with various mesenchymal cells," Tissue Engineering, Part A, vol. 15, no. 2, pp. 397-406, 2009.

[55] Y.-X. Cui, W. Kafienah, M.-S. Suleiman, and R. Ascione, "A new methodological sequence to expand and transdifferentiate human umbilical cord blood derived $\mathrm{CD}_{133^{+}}$cells into a cardiomyocyte-like phenotype," Stem Cell Reviews and Reports, vol. 9, no. 3, pp. 350-359, 2013.

[56] Y. Yamada, S.-I. Yokoyama, N. Fukuda et al., "A novel approach for myocardial regeneration with educated cord blood cells cocultured with cells from brown adipose tissue," Biochemical and Biophysical Research Communications, vol. 353, no. 1, pp. 182-188, 2007.

[57] R. Gaebel, D. Furlani, H. Sorg et al., "Cell origin of human mesenchymal stem cells determines a different healing performance in cardiac regeneration," PLOS ONE, vol. 6, no. 2, Article ID e15652, 2011.

[58] E. J. Lee, E.-K. Choi, S. K. Kang et al., "N-cadherin determines individual variations in the therapeutic efficacy of human umbilical cord blood-derived mesenchymal stem cells in a rat model of myocardial infarction," Molecular Therapy, vol. 20, no. 1, pp. 155-167, 2012.

[59] J. C. Wu, I. Y. Chen, G. Sundaresan et al., "Molecular imaging of cardiac cell transplantation in living animals using optical bioluminescence and positron emission tomography," Circulation, vol. 108, no. 11, pp. 1302-1305, 2003.

[60] S. Roura, J. R. Bagó, C. Soler-Botija et al., "Human umbilical cord blood-derived mesenchymal stem cells promote vascular growth in vivo," PLoS ONE, vol. 7, no. 11, Article ID e49447, 2012.

[61] M. A. J. Iafolla, J. Tay, and D. S. Allan, "Transplantation of umbilical cord blood-derived cells for novel indications in regenerative therapy or immune modulation: a scoping review of clinical studies," Biology of Blood and Marrow Transplantation, vol. 20, no. 1, pp. 20-25, 2014.

[62] D. Ilic, C. Miere, and E. Lazic, "Umbilical cord blood stem cells: clinical trials in non-hematological disorders," British Medical Bulletin, vol. 102, no. 1, pp. 43-57, 2012.

[63] S.-W. Kim, H. Han, G.-T. Chae et al., "Successful stem cell therapy using umbilical cord blood-derived multipotent stem cells for Buerger's disease and ischemic limb disease animal model," Stem Cells, vol. 24, no. 6, pp. 1620-1626, 2006.

[64] S. Roura, C. Gálvez-Montón, and A. Bayes-Genis, "Umbilical cord blood-derived mesenchymal stem cells: new therapeutic weapons for idiopathic dilated cardiomyopathy?" International Journal of Cardiology, vol. 177, no. 3, pp. 809-818, 2014.

[65] Y.-F. Hu, J. F. Dawkins, H. C. Cho, E. Marbán, and E. Cingolani, "Biological pacemaker created by minimally invasive somatic reprogramming in pigs with complete heart block," Science Translational Medicine, vol. 6, no. 245, Article ID 245ra94, 2014.

[66] M. R. Copley and C. J. Eaves, "Developmental changes in hematopoietic stem cell properties," Experimental and Molecular Medicine, vol. 45, article e55, 2013.

[67] G. M. T. Guilcher, C. V. Fernandez, and S. Joffe, "Are hybrid umbilical cord blood banks really the best of both worlds?" Journal of Medical Ethics, 2014. 


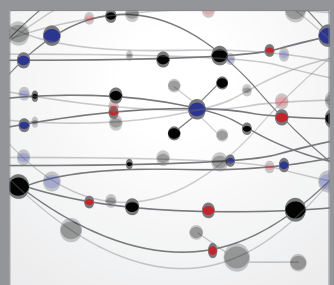

The Scientific World Journal
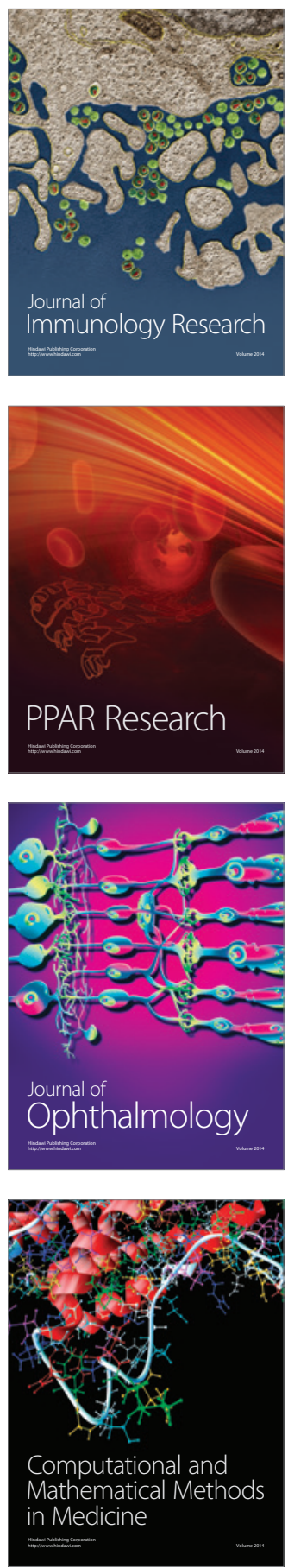

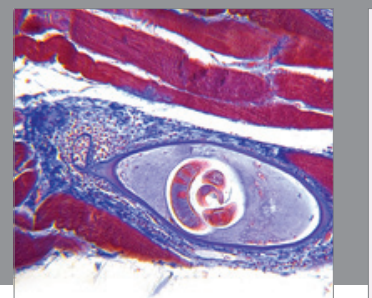

Gastroenterology

Research and Practice
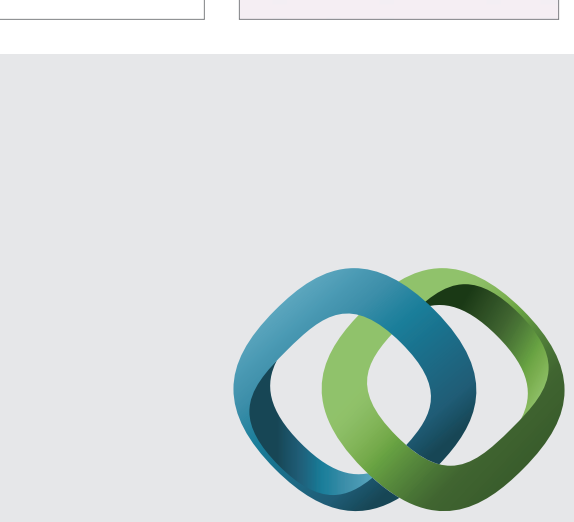

\section{Hindawi}

Submit your manuscripts at

http://www.hindawi.com
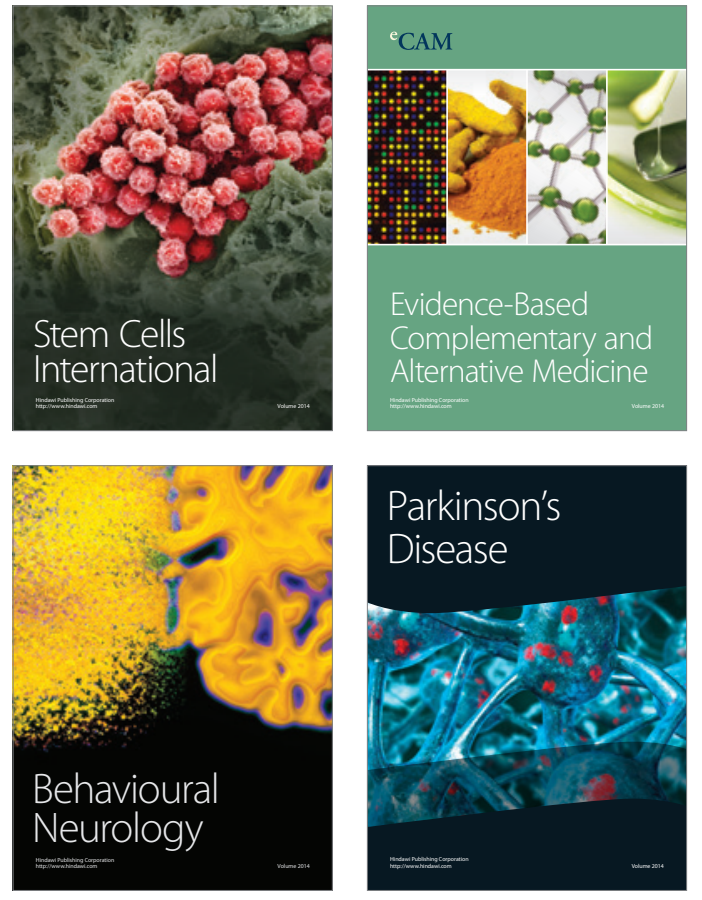
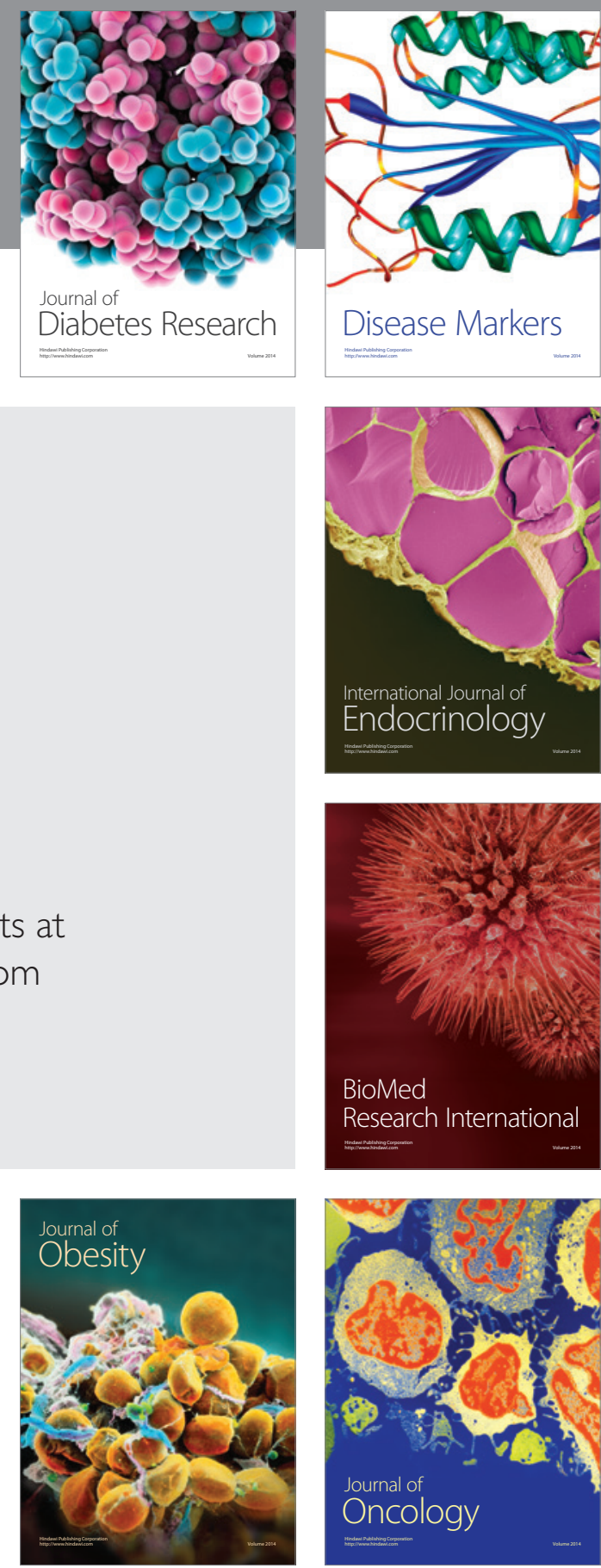

Disease Markers
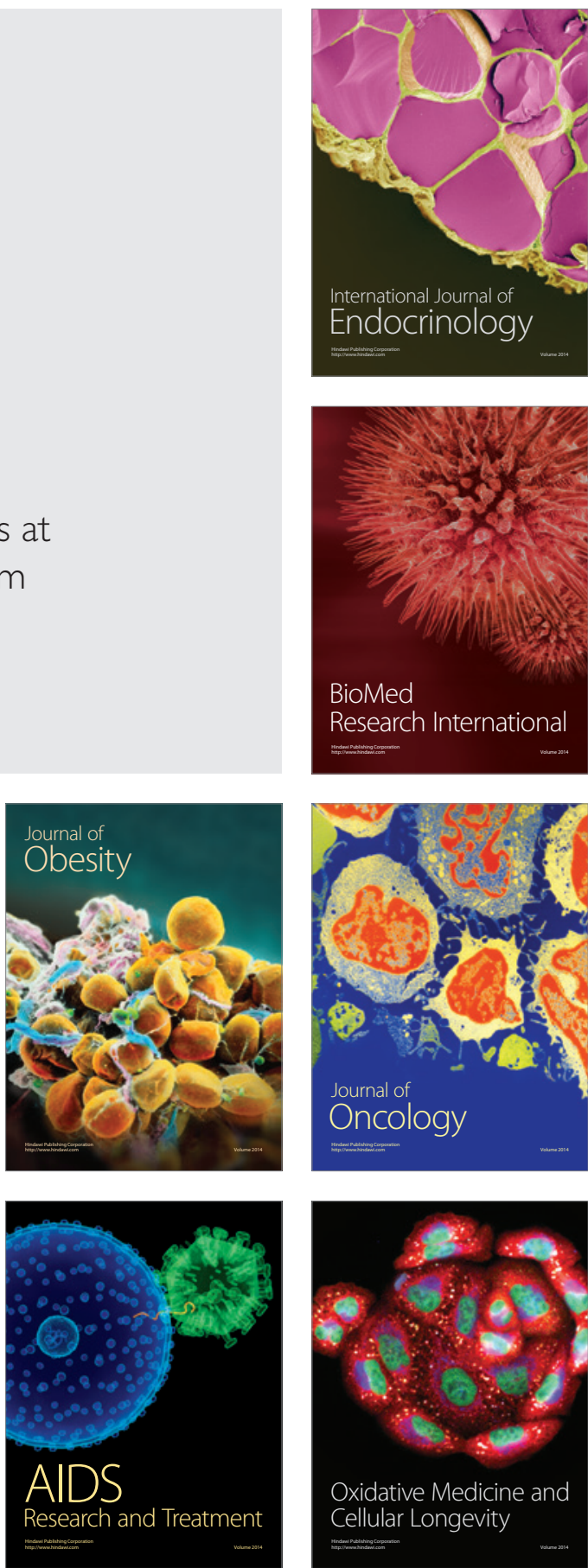